\title{
WANDERING ABOUT MINERALOGY AND PETROLOGY
}

\author{
Katagas Ch. \\ Department of Geology, Section of Earth Materials, University of Patras, \\ 26500 Rio,Greece; C.Katagas@upatras.gr
}

\begin{abstract}
Over the past few years an intense amount of research on various themes stimulated the development of Mineralogy and all its diversity, and many exciting discoveries have been made. New or technologically developed analytical and experimental methods such as ion microprobe, powerful MAS NMR, LA-ICP-MS, IR, Raman, XAS spectroscopies, beams of high intensity, Synchrotron radiation that enhanced the sensitivity of conventional spectroscopic and XRD techniques, beams of neutrons, widely available information and tremendous computing and modelling facilities have turned out to be excellent tools, promoting the ability of mineralogy in solving global and societal challenges.

Mineralogy today offers insights into important scientific issues, including sustainable development, evolution of the Earth and origins of life, deep Earth processes, physics and chemistry of Earth materials, fluids, magmas, igneous rocks and time scales, archaeomineralogy, nano-, geo-, and bio- environmental sciences.

The mineralogical sciences today are going through a period of rapid expansion and diversification and this trend is going to continue in future. There is now great potential for much interesting work in the latter areas but also the need to somehow protect the coherence of our discipline.
\end{abstract}

Key words: Mineralogy, Petrology, Late developments.

\section{Introduction}

When the president of this congress did me the honor to invite me as a keynote speaker, I decided to present a journey through the late achievements in the fields of mineralogy and petrology. I soon realized that the presentation of such a topic in a short lecture is a very difficult task but on the other hand I was very pleased because I would have the opportunity to argue on some erroneous comments we usually hear from some other fellow Earth scientists who think that mineralogy and petrology are fading-away.

Time and space restrictions impede this lecture of covering in detail such a huge topic and the progress that was made in all mineralogical and petrological sub-disciplines. What I have dealt with here is what has caught my own attention over the last few years, thus I may not have given due emphasis to some other important fields of mineralogy and petrology. I have undoubtedly been influenced in my choice and emphasis on topics of my own background and this article was written to give my own "snapshot" view rather than a fully academic analysis. It was not possible to mention here all the references I have used to present the progress was made in the various fields of mineralogy and petrology. In presenting the advances in each field I have roughly followed the list of the themes organized by the international program committee for the 2010 Goldschmidt conference. The interested reader 
may find authoritative contributions to each of the themes starting from those of the committee leaders for the individual themes (http://www.goldschmidt2010.org/themes).

Taking into account the central theme of the congress, I will start with some thoughts on the theory and practice of sustainable development and mineral resources. Sustainability of the Earth can be defined as the maintenance of the Earth systems and the use of any renewable resources they provide, at rates which guarantee the continuity of their viability. The strongest links between Earth's sustainability issues and mineralogical sciences exist in the areas of mineral- water and mineral-atmosphere interactions, in the role of minerals as economic resources, and in the environmental consequences of mining and the remediation of polluted areas.

Minerals always were and always will be in the service of mankind providing the necessary raw materials that present and future economic activity demands, in order to drive modern or future civilization (Hochella, 2002). There would be some who would argue that the concept of sustainable resources cannot be applied to the non-renewable mineral resources. This matter, however relates both to the discussion of whether the mineral resources should be conserved in some way for the benefit of future generations (intergenerational consideration) and to the environmental consequences of mineral extraction.

Mineral resources may not be essential for simple human survival, but are essential for human well being. Considering the human population dynamics, the availability of these non renewable resources will most likely be in overall decline (Hochella, 2002) unless we find ways to assist the sustainable development by "sustaining the unsustainable" mineral resources. Better knowledge of the understanding and sustainable use of minerals, public pressure to the mineral extracting, processing and using industries to move towards technologies enabling "more to be done with less", are very important issues. Mineralogy, petrology and geochemistry, as well as other geological branches drive our basic understanding of the natural environment. There is now the recognition that if we claim for sustainable development, emphasis must be placed on sustaining the knowledge basis, on which our future strategies for sustainability at all levels must be founded (Cook and Johan, 1994). Progress in our understanding of the processes in systems that support the human habitation of this planet, especially in the interaction of minerals with the hydrosphere, atmosphere and biosphere can play a key role in dictating the sustainability of our planet.

\section{Evolution of the Early Earth and origins of life}

Progress in understanding the evolution of the Early Earth has been dramatic in the last years. There are recent articles focusing on evidence that the oceans, continental crust and some form of plate tectonics all existed four billion years ago, and possibly even earlier (see Nutman, 2006).

The oldest known rocks are found in Acasta, Canada $(4.0 \mathrm{Ga})$ and recently, isolated detrital zircons, derived from unknown rocks from localities in western Australia, have provided evidence for 4.4Ga. The existence of zircon grains as old as $4.4 \mathrm{Ga}$ indicates that small amounts of granitic (sensu lato) protocontinent existed at that time and that the continent building processes were well under way by then.

Recent studies on the three major components of the Archean Greenstone belts, (tonalite-trondhjemitegranodiorite, TTG) and layered anorthosite complexes provide critical information on petrogenetic and geodynamic processes operated in the early Earth. Greenstone belts are dominated by: a) a komatiite-basalt association erupted in the form of intra-oceanic plateaus or alternatively continental flood sequences and b) a bimodal tholeitic to calc-alcaline basalts and dacites association, erupted in a magmatic arc setting. TTGs display diverse geochemical compositions and constitute 70 to $80 \%$ of the surviving Archean crust. Anorthosite complexes are suggested to be a key component of the early crust but their petrogenesis and tectonic setting are poorly constrained. 
Contributions that present innovative and integrated micro-analytical approaches to study inclusions in Hadean zircons and chemical and isotopic biosigniatures in Archean and Paleoproterozoic rocks, including iron formations, carbonates, shales, basalts, sulfate and phosphate rich rocks, provide exciting new avenues to reconstruct paleoenvironments.

Mineralogy offers insights into the debate on the origins of life, for various minerals may have played many different roles on the transition from geochemistry to biochemistry (see Hazen, 2005). Laboratory investigations and theoretical modeling explore the potential roles played by interactions between prebiotic molecules and mineral surfaces in promoting the mechanisms whereby molecules such as amino acids and nucleic acid fragments can bind to mineral surfaces leading possibly to the emergence of biological systems.

According to Ferris (2005) montmorilonite may have played a central role in the evolution of life. Ferris and co-workers (1989) have shown experimentally that Na-montmorilonite can adsorb organic compounds and can catalyze the formation of the first self-replicating RNA oligomers required for the origin of the first life in a protective environment. He suggested that life based on RNA preceded current life which is based on DNA and protein molecules.

One of life's most puzzling characteristics is that the basic constituents of the living organisms are chiral, but only L-amino acids (Laevo) are present in proteins and only D-nucleotides (Dextra) are present in nucleic acid. Hazen (2004) suggested that chiral mineral surfaces may have played a key role in separating left-from right-handed molecules or in catalyzing chiral synthesis reactions, since certain crystal faces of common minerals, like quartz and calcite display an aptitude for adsorbing handed molecules.

\section{Deep Earth processes: Core and mantle}

There has been a tremendous development in our understanding of the processes in the Earth's interior, coming from laboratory and computer experiments. Such experiments try to recreate the enormous P-T conditions which prevail in the deep Earth; measure the properties of minerals under such conditions; and study mantle rocks found at the surface. By comparing mineral properties at high $\mathrm{P}$ and $\mathrm{T}$ with geophysical observations we acquire information on the mineralogy, composition, temperature, deformation and structure of the Earth from the top of the mantle to the center of the planet.

Understanding of the deep Earth has been aided by new developments in diamond anvil cell and the large volume press technology combined with in situ XRD, spectroscopy and imaging techniques at synchrotron facilities. Recent advances in mass spectrometry, in particular, allow the stable isotope compositions of elements such as $\mathrm{Mg}, \mathrm{Si}$, and the transition metals to be determined at unprecedented levels of precision. In trace element research is now possible to measure mobile gas partitioning and trace element partitioning in mineral-water, mineral-melt, metal-silicate and metal-metal systems. Based on these data, quantitative models have been constructed that contribute to our understanding of a wide range of planetary differentiation processes, including crust and core formation, magma generation at ridges and hot spots, and element mobilization in subduction settings.

A phase transition of $\mathrm{MgSiO}_{3}$ perovskite to the higher-pressure form post-perovskite was recently discovered (Murakami et al., 2004) at P-T conditions $\left(120 \mathrm{GPa}, \sim 2500^{\circ} \mathrm{K}\right)$ resembling those occurring in the vicinity of the Earth's core-mantle boundary. This phase transformation is considered to be a possible cause for the $\mathrm{D}^{\prime \prime}$ discontinuity, may explain many of the seismic features of the $\mathrm{D}^{\prime \prime}$ layer, and is one of the few available means by which the thermal structure of the deepest mantle can be determined. A review of the early 2009 status concerning the structure, materials and dynamics of the lowermost mantle was presented by Trønnes (2009) and a description of the labora- 
tory-based methods used in the discipline of mineral physics may be found in articles by Bass and Parise (2008), Bass et al., (2008), Karato and Weindrer (2008).

The developments in analytical methods provided the means to study composition, textures and microscale mineralogy of lithospheric mantle derived peridotites and eclogites at the micro and nano scale, in addition to what can be learned from whole rock major and trace element or isotopic analyses of the samples. Such studies of mantle rocks and minerals from continental and oceanic environments considerably widened our knowledge about the composition of the Earth's mantle but also about processes that changed its nature through time. Recent geochemical and geophysical studies tend to agree that material injected into the mantle at subduction zones is responsible for the compositional heterogeneity of the mantle and the creation of mantle reservoirs. Geochemical studies have highlighted the need for heterogeneous pyroxenite-peridotitesediment mixtures to explain magmatism in oceanic and continental provinces. Seismic tomographic studies give evidence for subduction of oceanic lithosphere through the $660 \mathrm{~km}$ discontinuity and consequent return flow or upwelling of lower mantle into the upper mantle beneath hot spots and ocean ridges.

It is now generally accepted that oceanic basalts convey information about the chemical composition, thermal structure and dynamics of the mantle. It has been suggested that we can read the mantle signature in basalt compositions. But how mantle properties are translated into basalt compositions? Furthermore, do spatial patterns observed in the composition of oceanic basalts directly reflect mantle heterogeneity or, alternatively, they originate from regional-scale variations in melting behavior? These are issues that remain unresolved.

A number of recent studies focus on fluid-mineral interactions in deep crust and mantle. The quantification of the properties of fluids, particularly $\mathrm{C}-\mathrm{H}-\mathrm{O}-\mathrm{Si}$-bearing fluids, and their interactions with minerals in the deep crust and mantle is very important for understanding processes such as subduction, the generation of metamorphic fluids, the formation of deep mineral deposits and the deep carbon cycle. Field studies of high pressure rocks affected by fluids and experimental and theoretical studies of fluid properties, mineral solubilities and aqueous complexing at high $\mathrm{P}$ and $\mathrm{T}$ improve our understanding of these interactions.

Contributions to the study of the composition and structure of the continental lithosphere provide growing evidence for the importance of refertilization and deformation for the compositional evolution of the continental lithospheric mantle. Our models for the origin, chemical composition, physical properties and dynamics of the deep continental lithosphere are based mostly on magma-borne mantle fragments; however recent studies suggest that these fragments do not actually represent a mantle region. Combined efforts by petrologists, geochemists, geophysicists and field geologists may contribute in unraveling this and other lithosphere's secrets.

\section{Physics and chemistry of Earth materials}

Contributions to the study of chemical and biological processes at mineral surfaces have seen an intensive thrust in the last few years, primarily because of the new developments in the instrumental techniques that we can use to study surfaces at the atomic or near atomic level. Recent research of great interest includes fundamental molecular-scale mineral/microbe/water interface processes that impact the speciation, transport and potential bioavailability of the contaminants in our environment.

Of interest are also hydrogeochemical and mineralogical studies on low permeability sedimentary and crystalline rocks that limit fluid flow and solute transport. These rocks are important in the waste management, petroleum exploration and development, carbon dioxide sequestration and in groundwater protection and development. 
Uranium in the environment, in natural deposits or in anthropogenic systems (e.g. mine waste receiving areas, radiogenic pollutants), is a concern to humans because of the potential for habitat contamination by radiotoxic constituents and the degradation of ground water quality. One of the key issues in embracing a much-expanded nuclear option for energy production is the safe disposal of the nuclear wastes (Ewing, 2006). Issues such as the basic geochemistry of uranium, the origin of exploitable uranium deposits, the dispersal of mill tailings and the disposal of depleted uranium or the products of multiple reprocessing schemes need basic working knowledge of Earth systems.

Significant knowledge has been acquired on the interactions of metals with clays, including trace metal fate transport and retardation, and in particular issues concerning radioelement (e.g. U) migration in natural systems, in radioactive waste disposal sites or in engineered barriers.

Clays have high specific surface area and reactivity, they are able to efficiently retard metal migration in the geosphere, and to control natural biochemical cycles of many trace elements in soil and freshwaters. Almost universally, bentonite is considered an important component in nuclear waste repositories as part of a multi barrier system (Pusch, 2006). It provides a tertiary engineered buffer by: a) limiting the entry of water into the waste b) contributing to the retention of radionuclide in the case of a leak c) assisting in dissipating heat from radioactive decay and d) protecting the radioactive waste bearing canisters against mechanical shock.

Current efforts in carbon dioxide sequestration through geological storage and mineral carbonation render additional motivation to further our understanding of the mineralization in the carbonate systems. Mineral carbonation could be accomplished by reactions between $\mathrm{CO}_{2}$ with divalent cations such as $\mathrm{Ca}^{+2}, \mathrm{Mg}^{+2}$ and $\mathrm{Fe}^{+2}$ to form carbonate minerals. Source for the divalent cations could be silicate minerals such as forsterite $\left(\mathrm{MgSiO}_{4}\right)$ or anorthite $\left(\mathrm{CaAl}_{2} \mathrm{Si}_{2} \mathrm{O}_{8}\right)$. Basalts are considered to be among rocks with best $\mathrm{CO}_{2}$ storage capacity providing vast in situ carbon-mineralization sites throughout the world (Goldberg et al., 2008). Large efforts by the scientific community (Mineralogists/Petrologists/Geochemists) are still required to ensure that the in situ $\mathrm{CO}_{2}$ sequestration in basalt or ultramafic rocks is technologically and economically viable.

Atmospheric dust is generated through a wide range of natural and human activities. Research on the particulate matter (PM) has been focused primarily on organic particles produced through combustion processes (e.g. coal combustion, forest fires). Inorganic dust is also abundant in the atmosphere and has major impacts on e.g. climate, oceanic nutrient levels and even traffic. Recent research focuses on the mineralogical, geochemical and isotopic characterization of both anthropogenic (combustion, abrasion, construction) and naturally occurring inorganic dust (e.g. volcanic eruptions or continental erosion) with contributions on topics such as single particle mineralogical characterization, isotopic tracing, inorganic organic PM interaction (e.g. adsorption), nutrient transport, quantitative distribution and source allocation of various PM types, and the interaction of PM with soils, plants, glaciers, oceans and climate.

\section{Evolution of the oceanic crust and its hydrothermal systems}

Hydrothermal activity at oceanic spreading centers plays a critical role in the chemical, physical and thermal evolution of the oceanic crust and it is strongly influenced by the dominant tectonic setting. Recent work has highlighted the diversity of hydrothermal systems both in the near ridge high temperature environment and off axis. Research topics such as fluid rock interaction, phase separation, magmatic degassing, the formation of metal-sulfide deposits and metamorphic reactions are now focusing on processes in crust formed at slow spreading rates versus processes at faster spreading rates.

\section{Fluids, magmas and hydrothermal ore formation}

Fluids and melt inclusions are our best source of information concerning the composition, temperature and 
pressure of fluids associated with a wide range of geological processes in various geologic environments and times, including sedimentary basins, hydrothermal ore deposits, volcanic systems, subduction environments the upper mantle and diamond source regions and ultra high pressure metamorphic environments.

Economic geologists are increasingly recognizing that hydrothermal ore forming processes may have their roots in magma chambers in the upper mantle suggesting thus a vertical evolution of hydrothermal ore-forming systems.

Due to the unique role of nanoscale phases as agents of elemental transport and enrichment in ore systems, research on various aspects of nanomineralogy applied to mineral deposits, using all types of high resolution instrumental techniques (and computational methods) including HRTEM, HRSEM, SIMS, synchrotron XAS, XPS, AFM/AST and atomic modeling applications, has been significantly increased.

Microanalytical tools are also increasingly used for in situ microanalysis of single crystals of zircon, titanite, apatite and other accessory phases. The broad scale interest in single crystal mineral analyses stems from the limitations of whole rock trace element analyses in accessing the history of complex processes undergone by a single sample. Analyses of some accessory phases have wide potential applications, providing constraints on time, temperature, elemental and isotopic composition, magmatic oxidation state and fluid-melt evolution, among many others, from that same mineral grain.

\section{Metamorphism over multiple length and time scales}

Studies on mineralogical, petrological, stable /radiogenic isotope characteristics, microstructures, experimental and numerial modeling related to deeply subducted high and ultrahigh pressure metamorphic rocks, representing both oceanic and continental crusts, and fragments of the deep mantle, provided new insights into the global geodynamic processes operating in Earth's deep interior.

Following the worldwide recognition of UHP metamorphic rocks in more than 25 terranes, UHP metamorphism is no longer considered an "exotic" process; its significance affects all other disciplines of solid earth sciences, particularly petrology, geodynamics, global tectonics, seismology and geochemical cycling. During the last two decades diamond was discovered as micro-inclusions within garnet and zircon in about 10 localities of crustal metamorphic terranes. Due to these discoveries the PT diagram of metamorphic conditions realized by the Earth's crust had to be extended to 40kbar, equivalent with burial depths of about $140 \mathrm{~km}$. More recent research, based on modern nanoscale techniques led to the discovery of new indicator phases/associations for UHP-metamorphism $\left(\mathrm{TiO}_{2}\right.$, majoritic garnet, supersilisic titanite and clinopyroxene, pseudomorphs after stishovite, high-K clinopyroxene) which require continental subduction of at least $300 \mathrm{~km}$. As a result of the increasing role of UHP metamorphism in geosciences, in addition to important contributions on regional UHP-provinces, numerous scientific contributions have focused on topics such as high pressure experiments, computer modeling, geochronology, trace element geochemistry, Raman mapping, using techniques such as synchrotron infrared spectroscopy- nanosecondary ion mass spectrometry and diamond-anvil-cell technology.

Utilization of monazite, xenotime and zircon for dating a series of events considering recrystallization or partial alteration due to fluids and/or melts has gained great strides over the last decade. Complex textures seen in these accessory minerals can now be interpreted in terms of origins, history and chemical nature of the host rock, integrating thus geochronology, petrology and geochemistry. Current developments in zircon research, for example, is of fundamental importance. Based on detailed in situ isotopic, chemical, spectroscopic and microtextural studies of complex zircon crystals at high spatial resolution, or even at the scale of individual growth zones within a single grain, researchers can now link zircon ages to metamorphic or igneous petrogenetic events. 
In addition, the oxygen isotope ratio of zircon can be used to discriminate between new crust (mantle derived) and crust that has been reworked (Valley, 2003; Harley and Kelly, 2007). This approach is even more powerful when combined with zircon $\mathrm{U}-\mathrm{Pb}$ data and $\mathrm{Hf}$ isotope information on the same analyzed grains.

Some recent studies link metamorphic and igneous processes at subduction zones. Subduction-related metamorphic rocks from some localities provide petrological and geochemical evidence for large fluxes of aqueous fluids. Arc lavas contain abundant evidence for the involvement of aqueous fluids in their production. Research on eclogite-Arc magma connection by fluid introduction and transport at metamorphic conditions, fluid transport in the mantle wedge and slab-derived fluid contributions (volatiles, trace elements, isotope ratios) to arc magmas, provide new insights into the processes of fluid production, transport and evolution that ultimately lead to the generation of arc magmas.

Recent developments in metamorphic petrology and isotope geochemistry do permit increasingly accurate determinations of PT conditions of metamorphic samples, deformation analysis, geochronological constraints on the rates of orogenetic processes and forward models of orogenesis. However, continuing advances in understanding of the transport of elements and isotopes indicate that it is necessary to focus and move towards a scale heretofore inaccessible to traditional optical microscopy. At the nanometer scale, coupled dissolution/reprecipitation has already emerged as a crucial process. Ongoing research on metamorphism promotes the linkage of different methods to tackle macroscale to microscale issues in topics such as the tectonic affinity of subducted continents, transition from oceanic subduction to continental collision, crust mantle interaction during continental subduction-exhumation, time and duration of HP/UHP metamorphism, fluid effects on phase equilibria and P-T estimates, generation and action of aqueous fluid and hydrous melt, element and isotopic mobility, scale and magnitude of crustal melting, syn- and post-collisional magmatism, accessory minerals and trace elements. Metamorphism retains a dynamic and essential role for understanding the whole Earth from crust to core and it is not restricted solely to experiments! We should bear in mind that, besides the use of various modern techniques, many of these pioneering investigations were only possible through observations using the polarizing microscope, which remains a fundamental tool in geosciences!

\section{Global element cycles and climate change}

Microorganisms are intimately involved in the biogeochemical cycling of metals and metalloids. Certain microbial processes solubilize metals thereby increasing their mobility, which may increase bioavailability and potential toxicity, whereas other processes result in immobilization and reduce bioavailability.

The nature of microbe-mineral interaction also involves habitat conditions such as nutrient availability, presence or absence of toxic elements or $\mathrm{pH}$ buffering that contribute to the success or failure of a microbial consortium. The metabolic processes of the colonizing consortium influence mineral weathering, releasing, for example, limiting nutrients to the microorganisms (Bennet et al., 2002). Research on mineral-microbe interactions is an area of current and future expansion and is of great importance for both the mineralogical community and the advancement of the Environmental sciences.

Biomineralization in the marine realm is also a very interesting topic with implications on the understanding of the mineralization processes in natural systems. Chemical and isotopic signatures within biominerals provide information about the environment in which the minerals areformed. However, the interpretation of these signatures is difficult because the physiological environment of the organism may differ from extracellular conditions. Unraveling these effects requires an understanding of the processes of biomineralization which can be gained by laboratory culturing, investigated by experimental and theoretical techniques. 


\section{Nano-Geo-Environmental science: A new frontier in mineralogy}

Recent contributions reveal a nanotechnology revolution for the geosciences. Reviews of the field and its development may be found in contributions by Wigginton et al., (2007), Navrotsky et al., (2008) and Hochella et al., (2008a). The manipulation of individual atoms and molecules through nanotechnology could have a big impact on alternative energy, resource extraction and pollution control.

Fuel cells are promising alternatives to conventional batteries and ultimately, a great many of aqueous solutions, of both natural and artificial origin, will become nontraditional resources. Waste water, acid mine drainage, seawater or saline lakes, which often are considered as problems, could become potential sources of materials with the help of molecular separation techniques, and as the molecular separation techniques mature, they will blur the distinction between a "pollutant" and a resource (Hochella, 2008b).

Nanoparticles (1 to 100 nanometers) are ubiquitous in the environment and can provide the majority of reactive surface area in many natural systems. They represent a transition phase between dissolved and true particulates. It is believed that they help to control the fate and transport of metals, radionuclides, organic contaminants and the cycling of nutrients showing unique, and sometimes difficult to predict behavior. They still lack a comprehensive description of their environmental functions, and to understand their role in geochemical and environmental processes we need to make progress in isolating them from natural media, analyzing and quantifying their properties, understanding reactions on a nano scale and the role that compositions and structure play in their behavior. Their properties can deviate significantly from those of a larger particle of the same phase and there are cases where bulk analogs to nanomaterials do not even exist. Due to the size of these particles, to look into the nanoworld, we need special techniques. Modeling, electron microscopy, spectroscopy and XRD are techniques that we can use to understand and predict nanoparticle behavior with respect to complex hydro-bio-geochemical processes. Synchrotron radiation based X-Ray techniques with high spatial and spectra resolution are suitable not only for the identification and characterization of nanoparticles on a trace element level, but also to explore and understand their interactions with the environment.

One of the major issues of research in recent years has been the interactions of nanoparticles with environmental pollutants and particularly the retention of radionuclides at the mineral-water interface. Such mineral-water interface reactions lead to the incorporation of radionuclides by solids. Although the reactions are not sufficiently understood, surface-catalyzed condensation processes include formation of nanoparticles, surface precipitates and solid solutions with the reaction host phase and may or may not be triggered by surface redox processes. Field and microscopy/spectroscopy based studies indicate that radionuclides can be transported by groundwater over several kilometers in short periods of time defying thermodynamically based conditions (Hochella, 2008). Novikov et al (2006) showed that 70 to $90 \%$ of the plutonium transport in groundwater is accomplished by way of ferric oxides less than $15 \mathrm{~nm}$ in size. Much remains to be learned from the characteristics and behavior of natural nanoparticles. Nanogeoscience is at a relatively early stage of development but it seems that the near future will be an exciting time of new realizations, discoveries and change.

\section{Analytical and experimental techniques}

During the last 30 years we see an almost continuous application of new or technologically developed instrumental techniques to mineralogy, petrology and geochemistry. In the study of mineral structures, the X-ray diffraction techniques have been revolutionized by modern computerization and can now be used in combination with other emerging or rejuvenated techniques such as neutron diffraction, Transmission Electron Microscopy and spectroscopic methods (UV, optical, IR, Raman, Mössbauer). Magic 
Angle Spinning, Nuclear Magnetic Resonance (MAS NMR) and X-Ray absorption (XAS) spectroscopies, as well as IR and Raman spectroscopies, are also effective with non crystalline materials and have been important techniques for the structural characterization of glasses and melts, providing insights into their short-range order-property relationships (Henderson, 2005, Calas et.al., 2006).

New methods, experimental and theoretical, emerge to provide means for materials synthesis, crystal growth and studies on mineral stabilities, reactions and assemblages at various conditions of pressure, temperature and composition. The conditions prevailed in the Earth's interior can be reproduced in the laboratory using laser-heated diamond anvil cells, which currently permit access to pressure-temperature conditions of 225 GPa and $5000 \mathrm{~K}$, respectively. We now have a better knowledge on the mineralogy of the deep Earth and a better understanding of the behavior of rocks and minerals under extreme P-T conditions.

A major revolution in mineralogy and petrology came from the development and use of the SecondaryIon Mass Spectrometer (SIMS, Ion microprobe). Ion Microprobe has the ability to analyze samples for trace REE, HFSE, light- lithophile elements and isotopes. It has proven very powerful for high spatial resolution (commonly $<30 \mu \mathrm{m}$ wide and $<1 \mu \mathrm{m}$ deep) microprobe dating of zoned minerals using radiogenic isotopes and as microprobe for stable isotope systems. The method is relatively non destructive, allowing multiple analyses to be performed within single grains or zones within grains. In addition, isotopes and trace element analysis using nanometer scale ion imaging techniques have been applied to various research areas, including fluid-rock systems, paleoclimate, and biochemistry. ICP-MS (Inductively coupled plasma mass spectrometry) has become one of the standard methods for mineral analysis for measuring isotopes. It utilizes several sample introduction techniques, including laser ablation (LA) and direct introduction of a solution in the ionization region. The LA- ICP-MS method employs a focused laser beam to ablate material from samples. The ejected matter is ionized using an Argon plasma before being passed through to a mass spectrometer.

Mass spectrometric techniques have shed light to many geological problems, including the geochronology of inclusions in a meteorite ( $4.566 \pm 0.002$ billion years); based on $\mathrm{W}$ and $\mathrm{Hf}$ isotopes it was found that the formation of the core in an iron meteorite took place within 10 million years of the beginning of the solar system. Other isotopic systems indicate that by $\sim 40$ million years Earth had differentiated and that by 200 million years melts had crystallized in the crust, forming zircons (See Sutton et al., 2006)

Zircon grains are highly resistant to weathering; they can survive multiple geologic events and can provide a wealth of information regarding the crystal and mantle evolution studies. Zircon, for example in HP rocks, often protects mineral inclusions formed at high pressures from retrogression during exhumation, preserves different growth domains within a single crystal and in this way documents different stages of the subduction-exhumation history, which can now be puzzled out using Zircon U- Pb data (Gebauer et al., 1997) and Hf isotope information. Furthermore, a recently developed geothermometer based on the Ti content of Zircon in equilibrium with rutile is important in relating Zircon growth to temperature (Watson et al., 2006).

A number of contributions emphasize on the covariation of chemical and isotopic tracers in minerals used for geochronology (e.g. zircon) and thermochronologic (e.g. titanite) investigations. However, it is critical to understand which geochemical traits can help us make distinctions such as: when a chronometer becomes a thermochronometer, how can thermochronometers be tied to other minerals in a given metamorphic paragenesis and how can combined isotopic and geochronologic information (e.g. $\mathrm{U}-\mathrm{Pb}, \mathrm{Hf}, \mathrm{O}$ in zircon) help us to better understand magmatic and petrogenetic processes.

One of the most remarkable changes that has taken place in the past decade is the development and operation of many technologically advanced research facilities at national or international laboratories focused on synchrotron light source or neutron scattering experiments. The research at these large scale 
laboratories has impact in most Earth Sciences disciplines, including mineralogy, petrology and geochemistry. Issue No.1 of the "Elements" magazine (Vol. 2, 2006) provided an overview of these User research facilities and interesting reviews on the capabilities of Synchrotron Radiation, Neutron and Mass Spectrometry techniques in tackling complex scientific problems related to Earth materials and geological processes (Brown et al., 2006 a, b; Sutton et al., 2006; Parise and Brown 2006).

Synchrotrons generate extremely intense radiation in the Infrared to hard X-ray energy range. The average brightness of synchrotron light is six to twelve orders of magnitude greater than that of conventional laboratory $\mathrm{x}$-ray sources, for example. The beams of the high intensity synchrotron radiation can be configured in many ways to perform scattering, spectroscopy or imaging experiments, they greatly enhance the sensitivity of conventional types of studies using IR, UV-visible and X-ray radiation and they reduce the experimental time enormously. Most X-ray based methods can be applied with high spatial resolution, including $\mathrm{X}$-ray diffraction at high $\mathrm{P}$ and $\mathrm{T}$, X-ray fluorescence, X-ray absorption fine-structure and computed microtomography. A simultaneous application of the techniques can lead to production of elemental maps with sub ppm sensitivity and determination of the speciation and mineralogy at selected locations of the material. Examples of synchrotron radiation research on geological materials are given in Brown et al., (2006).

Beams of neutrons can be tuned to have wavelengths comparable to typical interatomic spacings while simultaneously having energies that are comparable to the energies of thermal vibrations. Thus neutrons can uniquely give information about both the structure and the dynamics of the matter. Unlike scattering by $\mathrm{X}$-rays, the interaction between neutrons and atomic nuclei is nucleus specific, which means that cations, for example $\mathrm{Mg}^{2+}, \mathrm{Al}^{3+}, \mathrm{Si}^{4+}$, have distinctly different neutron scattering cross sections, thus neutrons are able to provide direct information about $\mathrm{Mg} / \mathrm{Al} / \mathrm{Si}$ ordering in minerals. Diffractometers and spectrometers have been designed to measure the intensity of the scattered neutron beam as a function of scattering vector, but spectrometers also measure as a function of energy change, at the same time. Diffractometers can be optimized for High resolution or high intensity and for measurements at High P and High T.

Other neutron diffraction methods that are becoming increasingly popular in mineral sciences are: small angle scattering, measurements of texture maps, measurements of strain distributions within mineral assemblages and total scattering. The latter is particularly useful for studies of disordered crystalline materials and glasses. Spectrometers have been designed for different frequency ranges to measure the dynamics of atoms within matter (including excitations such as harmonic lattice vibrations) and spin waves (including sound waves and High Frequency bond-bending vibrations such as O-H stretching vibrations) and even lower frequency diffusion motions (Sutton et al., 2006).

Scientific advances made possible by neutron sources in earth and environmental science research may be found in review articles by Brown et al., (2006 b) and Parise and Brown, (2006).

The latest generation of synchrotron x-ray sources and pulsed neutron sources are getting brighter and there are now new opportunities for scattering, spectroscopy and imaging studies of earth materials that were not possible some years ago. We have now the ability, by using third generation synchrotrons, to obtain element and phase distribution and phase identification at the $5 \mu \mathrm{m}$ level using a combination of micro- XRF mapping, micro XRD and micro XAFs. Many of these developments are ongoing, and the impacts of the synchrotron and neutron source based methods on their complementarity on earth Science research will be enormous.

\section{Thoughts on the near future roles of mineralogy and petrology}

The intent of this lecture has been not so much to provide a well- digested review of the state of affairs in a given subdiscipline but, rather, to convey the essence and excitement of research occurring 
on the frontiers of our Science. However, the question "Where is the frontier?" is rather naïve as the breadth and diversity of our science impart a very wide range of perspectives. To maintain harmony amongst us I would conclude saying that there are different kinds of frontiers in mineralogy and petrology and the criteria in assessing value and importance are very well known to those working in particular disciplines or subdisciplines.

Mineralogical sciences have undergone several major revolutions in the last two or three decades. They are now broader and more sophisticated sciences that have been benefited a lot from the revolution in experimental technology available to physical, chemical and materials sciences research. Mineralogy has become more quantitative, rigorous and mechanism orientated in terms of concepts taken from other sciences. Earth is now considered to be a materials- processing laboratory operating with time, distance, mass, pressure and temperature on an uncomparable large scale. Many of our strengths are built on the foundations and techniques developed to understand the basic physics, chemistry and biology underlying the Earth's formation and evolution.

We, as mineralogists and petrologists, are now seeing the future of our sciences in the application of innovative technologies and experimental methods in our research to understand many fundamental unsolved problems related to what is going on under our feet, how minerals react with water, how pollutants in groundwater, soil and air are transported and absorbed and how complex geochemical cycling takes place. Characterization of fine-grained materials (clays, amorphous phases) and nanomaterials and research work on reactions and processes such as absorption or dissolution and catalysis at mineral surfaces or at the interface between the solid mineral and the medium of interaction are areas of current and future expansion with fairly obvious impacts on the quality of life and the environment. The potential for biological treatment systems to decontaminate solid or fluid waste is enormous and represents one of the key research thrusts.

Perhaps the most significant technological development for mineralogy and petrology is the microfocus synchrotron beam. With synchrotron beams XAS spectra, XRD patterns and XRF, geochemical data may all be acquired with spatial resolution from micron sized particles. Already this has had a tremendous impact on studies of particular well- constrained mineralogical and petrological problems. We expect to see, in the future, several new facilities opened to ease the access problem. Important technological advances include also ongoing improvements to Scanning Probe Microscopy, Scanning Tunneling Microscopy and Atomic Force Microscopy. The development of STM and AFM surface microscopic techniques has given us the capability to study in depth processes such as crystallization, dissolution, absorption at the atomic level, and in situ.

There is now great potential for much interesting work in these areas. Microbeam analytical methods for trace element and isotopic analysis are now available and we expect that ion microprobes should become more common in small scale university analytical centers. The explosive increase in the use of the method will continue in the years to come, due to its capability of directly connecting petrography with trace element/isotope chemistry and its contribution to $\mathrm{U}-\mathrm{Pb}$ age determinations. There will be also demand for much work with this instrument applied to environmental specimens.

Of course studies on the particular themes cited earlier in this article will continue to be of critical importance for some years. Other subjects could as well be at the forefront of our scientific endeavours:

- Uptake and long-term sequestration of carbon in stable mineral phases remains of critical importance for study.

- Safe disposal of nuclear waste: the recent economic crisis and the high prices of petroleum and other fossil fuels have resulted to increased pressure on many governments for resurgence of interest in nuclear power or to invest more funds in nuclear power production. One of the key is- 
sues in embracing a much-expanded nuclear option for energy production is the safe disposal of the nuclear wastes. Environmental mineralogy has a critical role to play in evaluating the primary nuclear waste (Ewing, 2001, 2006) measuring radionuclide transport in the engineered and geologic portions of the barrier system and evaluating the models of risk that rely on a number of geochemical parameters (Wogelius et al., 2007).

- Study of glasses and melts: spectroscopic techniques, (particularly infrared and Raman, NMR, Mösbauer and X-Ray absorption spectroscopy) have recently begun to be applied to glass structure, as spectroscopic data on silicate glasses and melts are similar. Most work to date has focused on the short range structure of glasses. It is important for this work to continue in the next years with more wide range of glass compositions and the advanced synchrotron and neutron scattering techniques should play increasingly important role, providing important information on this topic. The study of glasses and melts is highly connected with the disposal of the nuclear wastes, as the most common practice has been to immobilize HLW in borosilicate glasses or according to recent work, in phosphates, including monazite, apatite and glasses (Oelkers and Montel, 2008).

\section{Mineralogy and petrology in the cross road: Diversification and Expansion or fragmentation?}

Environmental mineralogy and geochemistry, nanomineralogy, biomineralogy and mineral physics are intellectually close to the interfaces between Earth sciences and disciplines such as chemistry, materials science, microbiology, physics and structural molecular biology. However in all these areas of research the need for interdisciplinary cooperation between mineralogists and other specialists will continue to grow. Our community has the obligation to contribute our skills towards a better understanding of the issues and mineralogists are committed to enhancing and promoting the role of mineralogy in solving global and societal challenges.

A large amount of mineralogical work occurs in disparate fields, and many of us are not aware of the full range of the subjects because the work done is commonly not visible to the bulk Earth science community (Hawthorne, 1993). Thus, this great diversity has adversely affected the general view of mineralogy and many earth scientists are not conversant with the breadth and intellectual vitality of current work in mineralogy. Works on zeolites and clays are characteristic examples.

Natural zeolites have exciting surface and structural properties, they possess attractive absorption, cation exchange, dehydration - rehydration and catalysis properties, which contribute directly to their use; They are being used for example in construction, as hydroponic substrate for growing plants in space missions, in pollution control, in the handling and storage of nuclear wastes, in biotechnology and in many other applications. (see in Colella and Mumpton, 2000). Their atomic scale structure gives them interesting and useful catalytic properties, therefore, the characterization and synthesis of new zeolites have become of great interest to some sectors of the chemical industry. Thus, although many mineral scientists have played prominent roles in the study and development of the field of zeolites and some still play, most of the important zeolite characterization and synthesis works are now published in the chemistry literature or in specialized journals (e.g. Zeolites) rather than in the mineralogical literature. Almost unknown to all but the zeolite chemists and engineers are also everyday zeolite applications such as: 3-fold increase in yield of gasoline from petroleum using zeolite catalysts, higher octane number and lower pollutants in automobile exhausts, cleaner multi-pane windows from zeolite absorbing vapours, safer brakes in trucks and trains, deodorization of animal litter, barns, ashtrays, refrigerators, and athletic footwear, longer life of refrigerators and selective absorbents in nuclear waste (Smith,1999; Mumpton, 1999). Consequently, although much work by mineralogists, or of interest to mineralogists 
is done in this field, most earth scientists are largely unaware of this aspect of mineralogical work because these journals are normally obscure to most Earth Scientists.

Clay minerals are fine grained sheet silicates with extremely diverse chemical composition and structure, made of various configurations of tetrahedrally and octathedrally coordinated layers. They vary in size from amorphous materials to barely recognizable particles under a polarizing microscope. Proper identification of a clay mineral requires $\mathrm{X}$ - ray diffraction techniques, and optical microscopy does not really help much for their identification. Clay minerals are of great importance to many areas of Earth sciences, including sedimentology, geological engineering, environmental processes, hydrothermal and weathering processes and industrial mineralogy.

Most undergraduate Earth Science students have a feeling that clays are not "proper" minerals mostly because they cannot see them easily under the microscope. On the other hand clay mineralogy has withdrawn from the rest of mineralogy and now has separate societies, journals and meetings, to the general detriment of Mineralogy as a whole (Hawthorne, 1993). R.L Frost, in the highlights of the July, 2002 issue of Geotimes, wrote:

"Clay science is alive and well- but perhaps not in the traditional departments of geology and natural resources. In the new millennium, clay science is thriving in schools of Chemistry, departments of Engineering and research programmes of environmental science".

The following two passages are quoted from the president's of the International Association for study of Clays annual report (Bish, 2009):

"...As the global scientific Society faces increasing diversification of clay science, it is more important that AIPEA members actively participate in the life of our society. At the same time, there appears to be a renaissance in related sciences wherein clay minerals play an important role, in fields such as chemistry, biological sciences and materials science...".

"...Clay mineralogy has been experiencing renewed interest worldwide based on an explosion of activity of a variety of fields outside of traditional clay mineralogy. Perusal of many journals in chemistry, physics and materials sciences reveals significant interest in the fine grained materials that we all study and use...".

Of course we cannot put limits on what is Mineralogy and we must allow every flower to blossom. With such a cooperative research we will have an enormous impact of our discipline on important highly visible scientific issues that confront society today and on our scientific understanding of the mineralogical, geochemical and biological system we call Earth.

Mineralogy is going through a period of rapid expansion and diversification and the formal Mineralogical community (mineralogical associations and societies) needs bridges for our connection to one another within our broad discipline and for our connection to other fields such as environmental science, material science, solid state physics, biosciences and chemistry. More appreciations of the work done by all sectors of the community working on minerals would pull all these branches back into a coherent discipline. Mineralogists, petrologists and geochemists have to establish a larger collective presence. We all have to help to achieve this goal.

I strongly believe that the future of the Mineralogical sciences is very bright. There will be much research excitement in our fields in the years to come and we must try to attract the attention of talented students wishing really to study Earth sciences. Today, there is probably no standard answer to the question of what constitutes an ideal undergraduate geology curriculum. Nevertheless, the classical fields of Mineralogy and Petrology remain vitally important because they provide essential back- 
ground about Earth's materials, the geological processes that produce and affect them and they certainly have a huge impact in the quality of our life. However, we must also create space for the newer ideas and applications of our sciences. Existing courses could be enhanced, for example, by devoting time to discussions on the adsorption, cation exchange, dehydration and catalytic properties of minerals, which are important for the development of their applications. We must encourage the new generations of scientists to follow our field because at no previous time has there been so much excitement in mineralogy and petrology.

\section{Acknowledgments}

I thank T. Kotopouli and Y. Iliopoulos for reading and commenting on the manuscript.

\section{References}

Bass, J.D., Parise, J.B., 2008. Deep earth and recent developments in mineral physics. Elements, 4 (3), 157-163.

Bass, J.D., Sinogeikin, S.V., Li, B., 2008. Elastic properties of minerals: A key for understanding the composition and temperature of earth's interior. Elements, 4 (3), 165-170.

Benner, S. A., Caraco, M. D., Thomson, J. M., Gaucher, E. A., 2002. Evolution: Planetary biology - paleontological, geological, and molecular histories of life. Science, 296(5569), 864-868.

Bish, D., 2009. 2009 President's report. AIPEA Newsletter, 41, 1-3.

Brown Jr., G.E., Calas, G., Hemley, R.J., 2006a. Scientific advances made possible by user facilities. Elements, 2 (1), 23-30.

Brown Jr., G. E., Sutton, S. R., Calas, G., 2006b. User facilities around the world. Elements, 2 (1), 9-14.

Calas, G., Henderson, G. S., Stebbins, J.F., 2006. Glasses and melts: Linking geochemistry and materials science. Elements, 2 (5), 265-268.

Cook, P. and Johan, Z., 1994. Introduction: Mineral resources and sustainable developments: A workshop. Abstracts and background documents. Technical report WF/94/12, British Geological survey, U.K., pp. $10-13$.

Colella C. and Mumpton, F.A. (Eds), 2000. Natural Zeolites for the Third Millennium De Frede - Editore, Napoli, Italy, $484 \mathrm{pp}$

Ewing, R.C., 2001. The design and evaluation of nuclear-waste forms: Clues from mineralogy. Canadian Mineralogist, 39(3), 697-715.

Ewing, R.C., 2006. The nuclear fuel cycle: A role for mineralogy and geochemistry. Elements, 2(6), 331-334.

Ferris, J.P., 2005. Mineral Catalysis and Prebiotic Synthesis: Montmorillonite-Catalyzed Formation of RNA. Elements; 1 (3), 145-149.

Ferris, J.P., Ertem, G., Agarwal, V., 1989. Mineral catalysis of the formation of dimers of 5'-AMP in aqueous solution: The possible role of montmorillonite clays in the prebiotic synthesis of RNA. Origins of Life and Evolution of the Biosphere, 19 (2), 165-178.

Gebauer, D., Schertl, H., Brix, M., Schreyer, W. 1997. 35 ma old ultrahigh-pressure metamorphism and evidence for very rapid exhumation in the dora maira massif, western alps. Lithos, 41 (1-3), 5-24.

Goldberg, D.S., Takahashi, T., Slagle, A.L., 2008. Carbon dioxide sequestration in deep-sea basalt. Proceedings of the National Academy of Sciences of the United States of America, 105 (29), 9920-9925.

Harley, S. L. and Kelly, N.M., 2007. The impact of zircon-garnet REE distribution data on the interpretation of zircon U-pb ages in complex high-grade terrains: An example from the rauer islands, east antarctica. Chemical Geology, 241(1-2), 62-87. 
Hawthorne, F.C., 1993. Minerals, mineralogy and mineralogists: Past, present and future. Canadian Mineralogist, 31 (2), 253-296.

Hazen, R.M., 2004. Chiral crystal faces of common rock-forming minerals. In G. Palyi, C. Zucchi and L Cagglioti, Eds. Progress in Biological Chirality. New York: Elsevier, Chapter 11, pp.137-151.

Hazen, R.M., 2005. Genesis: Rocks, minerals and the geochemical origin of life. Elements 1, \#3, 135-137.

Henderson, G.S., 2005. The structure of silicate melts: A glass perspective. Canadian Mineralogist, 43 (6), 1921-1958.

Hochella, M.F., 2002. Sustaining earth: Thoughts on the present and future roles of mineralogy in environmental science. Mineralogical Magazine, 66 (5), 627-652.

Hochella Jr., M.F., 2008. Nanogeoscience: From origin to cutting-edge applications. Elements, 4 (6), 373-379.

Karato, S.-I. and Weidner, D.J., 2008. Laboratory studies of the rlheological properties of minerals under deep-mantle conditions. Elements, 4 (3), 191-196.

Mumpton, F.A., 1999. La roca magica: Uses of natural zeolites in agriculture and industry. Proceedings of the National Academy of Sciences of the United States of America, 96 (7), 3463-3470.

Murakami, M., Hirose, K., Kawamura, K., Sata, N., Ohishi, Y., 2004. Post-perovskite phase transition in $\mathrm{MgSiO}_{3}$. Science, 304 (5672), 855-858.

Navrotsky, A., Mazeina, L., Majzlan, J., 2008. Size-driven structural and thermodynamic complexity in iron oxides. Science, 319 (5870), 1635-1638.

Novikov, A.P., Kalmykov, S.N., Utsunomiya, S., Ewing, R.C., Horreard, F., Merkulov, A., et al., 2006. Colloid transport of plutonium in the far-field of the mayak production association, russia. Science, 314 (5799), 638-641.

Nutman, A.P., 2006. Antiquity of the oceans and continents, Elements 2, pp. 223-227.

Oelkers, E.H. and Montel, J., 2008. Phosphates and nuclear waste storage. Elements, 4 (2), 113-116.

Parise J.B. and Brown Jr., G.E., 2006. New opportunities at emerging facilities, Elements, 2, 37-42.

Pusch, R., 2006. Clays and nuclear waste management. In: F. Bergaya, B.K.G. Theng and G. Lagaly, Editors, Handbook of Clay Science, Elsevier, pp. 703-716.

Smith, J.V., 1999. Geology, mineralogy, and human welfare. Proceedings of the National Academy of Sciences of the United States of America, 96 (7), 3348-3349.

Sutton, S.R., Caffee, M.W., Dove, M.T., 2006. Synchrotron radiation, neutron, and mass spectrometry techniques at user facilities. Elements, 2 (1), 15-21.

Trønnes, R.G., 2009. Structure, mineralogy and dynamics of the lowermost mantle. Mineralogy and Petrology, 1-19.

Valley, J.W., 2003. Oxygen isotopes in zircon. Reviews in Mineralogy and Geochemistry, 53 (1), 343-385.

Watson, E.B., Wark, D.A., Thomas, J.B., 2006. Crystallization thermometers for zircon and rutile. Contributions to Mineralogy and Petrology, 151 (4), 413-433.

Wigginton, N.S., Haus, K.L., Hochella Jr., M.F., 2007. Aquatic environmental nanoparticles. Journal of Environmental Monitoring, 9 (12), 1306-1316.

Wogelius, R.A., Morris, P.M., Kertesz, M.A., Chardon, E., Stark, A.I.R., Warren, M., Brydie, J.R., 2007. Mineral surface reactivity and mass transfer in environmental mineralogy. European Journal of Mineralogy, 19 (3), 297-307. 
